\title{
Identification of birch pollen species using FTIR spectroscopy
}

\author{
Joanna Depciuch (1) Idalia Kasprzyk - Elzbieta Drzymała • Magdalena Parlinska-Wojtan
}

Received: 27 November 2017/Accepted: 27 June 2018/Published online: 4 July 2018

(C) The Author(s) 2018

\begin{abstract}
In this study, the morphology and chemical composition of pollen grains of six birch species (Betula utilis Doorenbos, B. dahurica, B. maximowicziana, B. pendula, B. pubescens and B. humilis) were examined to verify which of these features allow distinguishing them in a more unambiguous way. For this purpose, scanning electron microscopy and light microscopy, as well as Fourier transform infrared (FTIR) spectroscopy and curve-fitting analysis of amide I profile, were performed. The microscopy images show that the pollen grains of B. pubescens, $B$. pendula and $B$. humilis are similar in diameter and significantly smaller than those of others species, with the largest diameter observed for B. utilis Doorenbos. However, the results obtained from FTIR spectroscopy indicate that the chemical compositions of B. pubescens and B. pendula are similar, but B. humilis is outlaying. Summarizing, it is not possible to unambiguously state, which feature or which technique is the best for differentiating between the six chosen birch species. However, the study showed that
\end{abstract}

J. Depciuch $(\varangle) \cdot$ E. Drzymała · M. Parlinska-Wojtan Institute of Nuclear Physics Polish Academy of Sciences, 31342 Kraków, Poland

e-mail: joannadepciuch@gmail.com

I. Kasprzyk

Department of Ecology and Environmental Biology, University of Rzeszow, Zelwerowicza 4,

35-601 Rzeszow, Poland both techniques have potential for identification of birch pollen species.

Keywords Betula - Birch · FTIR spectroscopy · Pollen $\cdot$ Palynotaxonomy $\cdot$ SEM

\section{Introduction}

Modern plant taxonomy is based on anatomical and morphological, as well as on genetic, biochemical and physiological studies (APG II 2003). One of many features, which could be used in taxonomy, is the morphology of pollen grains. Pollen grains have a very large variety of forms. The most important taxonomic parameter is the surface sculpture of the cell wall termed exine. The other indicative features are shape, grain size, as well as number, type and position of the apertures (Erdtman 1952). The pollen grains are identified with different accuracies. Often, it is not possible to identify pollen grains to species level, as in the case of Betula, Alnus, Populus or Artemisia. For some species, it is possible to identify pollen grains only to higher taxonomic categories like family (Poaceae) and even type-Plantago major/media (Frenguelli and Kasprzyk 2015).

Attempts to distinguish Betula pollen grains to the level of species were undertaken by Birks (1968), Mäkelä (1996) and Caseldine (2001). These authors, 
using the biometric method, indicated that the smallest pollen grains are Betula nana (L.), followed by $B$. pendula (Roth.) and B. pubescens (Ehrh). They showed that although the diameter of pollen grains of some Betula species differs noticeably, the frequency distribution curves of the pollen sizes overlap; thus, it is difficult to reliably identify grains to species level. Birks (1968) indicated the diameter/pore depth ratio as good criterion to distinguish between $B$. pubescens and B. nana grains. Clegg et al. (2005) gave the threshold size for pore depth and diameter/pore depth ratio to distinguish pollen of tree from shrub birch species native for western North America. Blackmore et al. (2003) presented the key to determine the Betula pollen types such as $B$. pubescens type comprising $B$. pendula, B. pubescens ssp. carpatica, $B$. pubescens ssp. pubescens, $B$. pubescens ssp. tortuosa and $B$. nana type including $B$. nana and $B$. humilis (Schrenk). These types were distinguished based on the size and shape of grains, the sculpture of exine, as well as the structure of pores, especially the vestibulum.

Pollen analysis is still based on light microscopic observations. This method requires enormous experience and is additionally time-consuming. That is why more and more scientists seek for other solutions without losing the quality of identification and simultaneously simplifying the work. An alternative to microscopic analysis could be the identification of genetic material using techniques of molecular detection (Zhou et al. 2007; Parducci and Suyama 2011). Furthermore, pyrolysis mass spectrometry (PyMS) can also discriminate plants phylogenetically (Kim et al. 2004a, b). However, biomarkers determined by PyMS data cannot be deconvoluted to identify the chemical compounds (Kim et al. 2004a, b). This problem can be solved by Fourier transform infra red (FTIR) spectroscopy. Indeed, the pollen grains of some species are morphologically similar, but differ significantly in chemical composition; thus, these differences can be revealed by spectroscopic methods and visualized in the obtained spectrum. Pappas et al. (2003) were the first to demonstrate that infrared spectroscopy can be used for the determination of pollen grains to the species level, creating libraries of pollen spectra. Furthermore, they compared the results obtained from FTIR with light microscopy observations. Moreover, FTIR enables chemical analysis of pollen samples for plant phenotyping to study plant- environment interactions, such as influence of climate change, stress or pathogens (Bağcioğlu et al. 2017; Zimmermann et al. 2017; Lahlali et al. 2014). Furthermore, other authors used FTIR spectroscopy to determine the connection between the viability and the germination capacity (Buta et al. 2015). The attempts of discrimination and classification of allergy-relevant pollen using FTIR spectroscopy combined with multivariate statistical methods were made (Dell'Anna et al. 2009). In this work, the authors confirmed that the hierarchical cluster analysis provided valuable information about the reproducibility of FTIR spectra of the same taxon. The utility of infrared spectroscopy in palynology was demonstrated by Gottardini et al. (2007). They showed that it is possible to effectively apply this method for the determination of pollen grains to the species level. Moreover, using FTIR spectroscopy it was possible to identify grass pollen grains to subfamily level with an $80 \%$ success rate (Julier et al. 2016). This works are very important, because uniform morphology of different species of Poaceae (grass) pollen means that identification to below family level using light microscopy is extremely challenging. Large-scale studies on the identification potential of the pollen grains by means of infrared spectroscopy were initiated by Zimmerman and colleagues (2014). They successfully applied this technique to identify the pollen grains of coniferous plants, showing that pollen grains of closely related species with similar morphology distinctly differ in chemical composition (Zimmerman 2010). In their subsequent studies, they prepared spectra libraries of 300 different species belonging to 53 angiosperms families (Zimermann and Kohler 2014; Zimmermann et al. 2015, 2017).

FTIR spectra of individual pollen samples are different, and the most visible differences are in the spectral regions corresponding to vibrations originating from lipids, sporopollenin and carbohydrate. Spectral variability enables sufficient differentiation of plant-related families and genera (Zimermann and Kohler 2014, 2015), and even congeneric species (Bağcıŏlu et al. 2015; Zimmermann 2018). Furthermore, FTIR has been used in plant biology to differentiate between cell wall mutant plants (Stewart et al. 1997; Chen et al. 1997). Those studies showed that FTIR could be used to identify structural and architectural alterations in cell walls. 
The purpose of the investigation reported here is to compare the morphology and chemical composition of pollen grains of chosen birch species. For this purpose, infrared spectroscopy (FTIR), curve-fitting analysis of amide I profile, light and scanning electron microscopy (SEM) were applied. This study will allow determining whether morphological or chemical features are better for the distinction between birch species.

\section{Materials and methods}

\subsection{Pollen samples}

The study was carried out in Bolestraszyce Arboretum, SE Poland. This arboretum $\left(22^{\circ} 50^{\prime} \mathrm{E} ; 49^{\circ} 54^{\prime} \mathrm{N}\right)$ covers an area of nearly 29 ha. Given the undulating topography, the altitude ranges between 195 and $216 \mathrm{~m}$ a.s.l. The climate of the Bolestraszyce region is classified as warm temperate. The mean annual total precipitation and mean annual temperature are $600 \mathrm{~mm}$ and $8.2{ }^{\circ} \mathrm{C}$, respectively. The arboretum collection comprises 2200 taxa of trees and shrubs including native species, fruit trees as well as plants of foreign origin. For the present experiment, six birch species were chosen: B. pendula (Roth.), B. pubescens (Ehrh.), B. humilis (Shrank), B. maximowicziana (Regel), B. utilis (D. Don) Doorenbos and B. dahurica (Pall.). These species differ in origin, biology and environmental requirements. The first three species are native to the Polish flora; the remaining, nonnative, are planted in urban greenery, home gardens and do not occur in natural habitats. They are generally fast-growing, prefer light and tolerate dry, infertile soils. B. pendula is an important forest-forming species and is thus considered as key woodland pioneer species, growing well on infertile soils. The rarely occurring in Poland B. pubescens prefers fertile, fresh, wet and even swampy soils, which also prefers B. humilis. Pollen of each species was collected from several inflorescences in April 2016 during flowering phenophase. If the individuals pollinated abundantly, pollen was collected into an Eppendorf tube in situ. In other cases, the branches with inflorescences were taken to the laboratory and were put into containers with water for several days until the inflorescences started to release pollen. Collecting material from all species in the same location greatly reduces the influence of the habitat conditions like topoclimate, relief or soil on the chemical composition of pollen, which was demonstrated among others by Depciuch et al. (2016) and Zimermann and Kohler (2014). In such planned experiment, the chemical composition is only determined by 'species' variable.

\subsection{Light and electron microscopy observations}

The collected pollen was mounted in glycerogelatin with fuchsine after few days of sampling, which is recommended for observations and measurements under light microscopy. In microscopic samples prepared in such a way, the shape and size of pollen grains are not altered, as in the case of drying or after acetolysis (Reitsma 1969; Clegg et al. 2005). On microscopic slide, the pollen grains were arranged in a way that all the pores were in one plane (polar view). For each species, the size of 50 pollen grains was measured at $400 \times$ magnification with the Nicon Eclipse $\mathrm{Ci}$ light microscope using NIS software. Karlsdóttir et al. (2007, 2008) defined this size as the distance between two points situated one on the outer layer of exine and the other one on the pora tip.

Scanning electron microscopy was carried out on a TESCAN VEGA 3 SBH instrument equipped with a tungsten cathode. The pollen was deposited on a SEM stub sample holder covered with a carbon patch. The samples were imaged in high vacuum mode at $1 \mathrm{kV}$ accelerating voltage using the SE detector. The pollen samples were observed without being coated with gold or carbon. The pollen grains were collected during rainless season, therefore they were dry and it was not necessary to dry them additionally.

\subsection{FTIR measurements}

FTIR spectroscopy measurements were taken using a Vertex 70 (Bruker) spectrometer applying the attenuated total reflectance (ATR) technique, with multireflective, diamond side disk. The selected infrared radiation was the average IR range (400-4000 $\left.\mathrm{cm}^{-1}\right)$. To achieve $4 \mathrm{~cm}^{-1}$ spectral resolution, 64 scans were used. For each pollen sample, the same absorption bands corresponding to nucleic acids, proteins, polysaccharides, lipids and water were identified. Each measurement was taken in triplicates. In order to 
determine the structural changes in pollen grains, the second derivative of the spectra was calculated.

\subsection{Data analysis}

All spectra were treated with the OPUS software. The analysis of the secondary structure of the proteins was carried out by curve fitting using the GRAMS AI software from Thermo Scientific. The second derivatives were calculated from the ATR-FTIR spectra after smoothing over nine consecutive points. The absorption bands at low wavenumbers were free from features originating from water vapor, as judged from the peaks above $1750 \mathrm{~cm}^{-1}$. A straight baseline passing through the ordinate at 1700 and $1610 \mathrm{~cm}^{-1}$ was subtracted before the curve fitting. The baseline was again modified by the least-squares curve-fitting software, which allows for a horizontal baseline to be adjusted as an additional parameter to obtain the best fit. The second derivative spectrum was used to determine the initial peak positions for curve fitting, and the peaks were fitted using Gauss functions. The area under the entire band was considered as $100 \%$, and each component after fitting was expressed as a percent fraction.

\subsection{Statistical analysis}

Firstly, the normal distribution and the homogeneity of variances were checked using Shapiro-Wilk and Brown-Forsyth tests, respectively. The statistical hypothesis about the lack of differences among Betula species in respect to the diameter of pollen grains was tested using Kruskal-Wallis test. Dunn's post hoc test was applied for multiple comparisons. Statistical tests were tested with $\alpha \leq 0.05$. In order to indicate the groups of the individual species with the highest similarity with respect to the absorbance spectra, hierarchical clustering analysis (HCA) with Euclidean distance and Ward's algorithms was used. This method was applied for the ranges between 400 and $4000 \mathrm{~cm}^{-1}$ (entire spectrum) and 1500 and $1700 \mathrm{~cm}^{-1}$ (proteins region), as well as for entire spectra and mean diameter of grains for each species. In latter case, raw data were expressed in different units $\left(\mu \mathrm{m}\right.$ and $\left.\mathrm{cm}^{-1}\right)$; therefore, they were standardized before calculating the Euclidean distance. For HCA, average spectra of each sample were used.
Statistical and multidimensional analysis was performed using PAST software.

\section{Results}

\subsection{Shape and size of pollen grains}

SEM imaging did not reveal any differences in the shape of the pollen grains of different species (Fig. 1). No distinct differences in exine and pores morphology between the respective samples could be noticed. However, it is clearly visible that the pollen grains have different sizes (Fig. 1). It was confirmed statistically $(H=245.446 ; p<0.000)$. The $B$. utilis Doorenbos has the largest pollen grains (above $32 \mu \mathrm{m})$ followed by $B$. maximowicziana and $B$. dahurica, which pollen grains do not differ significantly from each other. The pollen grains of $B$. pubescens, B. pendula and B. humilis have similar sizes (from 22.168 to $23.104 \mu \mathrm{m}$ ) and are significantly smaller than the others. The pollen grains of $B$. humilis are smaller than $10 \mu \mathrm{m}$ from grains of $B$. utilis Doorenbos, and both species are characteristic by great variability (standard deviation values) (Table 1).

\subsection{Molecular composition}

Figure 2 shows the offset of the FTIR spectra indicating specific bonds for pollen from each site. Main absorption bands and their assignments are presented in Table 2. For each pollen sample, the same absorption bands corresponding to polysaccharides, proteins, lipids and water were identified (Table 2, Fig. 2). The low wave number region of the FTIR spectrum originates from the chemical bonds of polysaccharides $\left(1032,1000-1075 \mathrm{~cm}^{-1}\right)$ and proteins $\left(1460,1515-1570,1600,1650 \mathrm{~cm}^{-1}\right)$. The peak at $1738 \mathrm{~cm}^{-1}$ corresponds to stretching vibrations of the $\mathrm{C}=\mathrm{O}$ group, which evidences the presence of lipids. Vibrations observed in the FTIR spectrum at 2850 and $2930 \mathrm{~cm}^{-1}$ wave numbers originate from $\mathrm{CH}_{2}$ and $\mathrm{CH}_{3}$ vibrations of lipids, proteins and carbohydrates. The peaks at 3007 and $3300 \mathrm{~cm}^{-1}$ correspond to $\mathrm{C}=\mathrm{C}$ and $\mathrm{O}-\mathrm{H}$ vibrations (Rubio-Diaz et al. 2010; Mohani et al. 2014; Rather et al. 2014).

FTIR spectra (Fig. 2) show that in the five pollen samples (B. utilis Doorenbos, B. dahurica, B. maximowicziana, B. pendula, B. pubescens), the same 

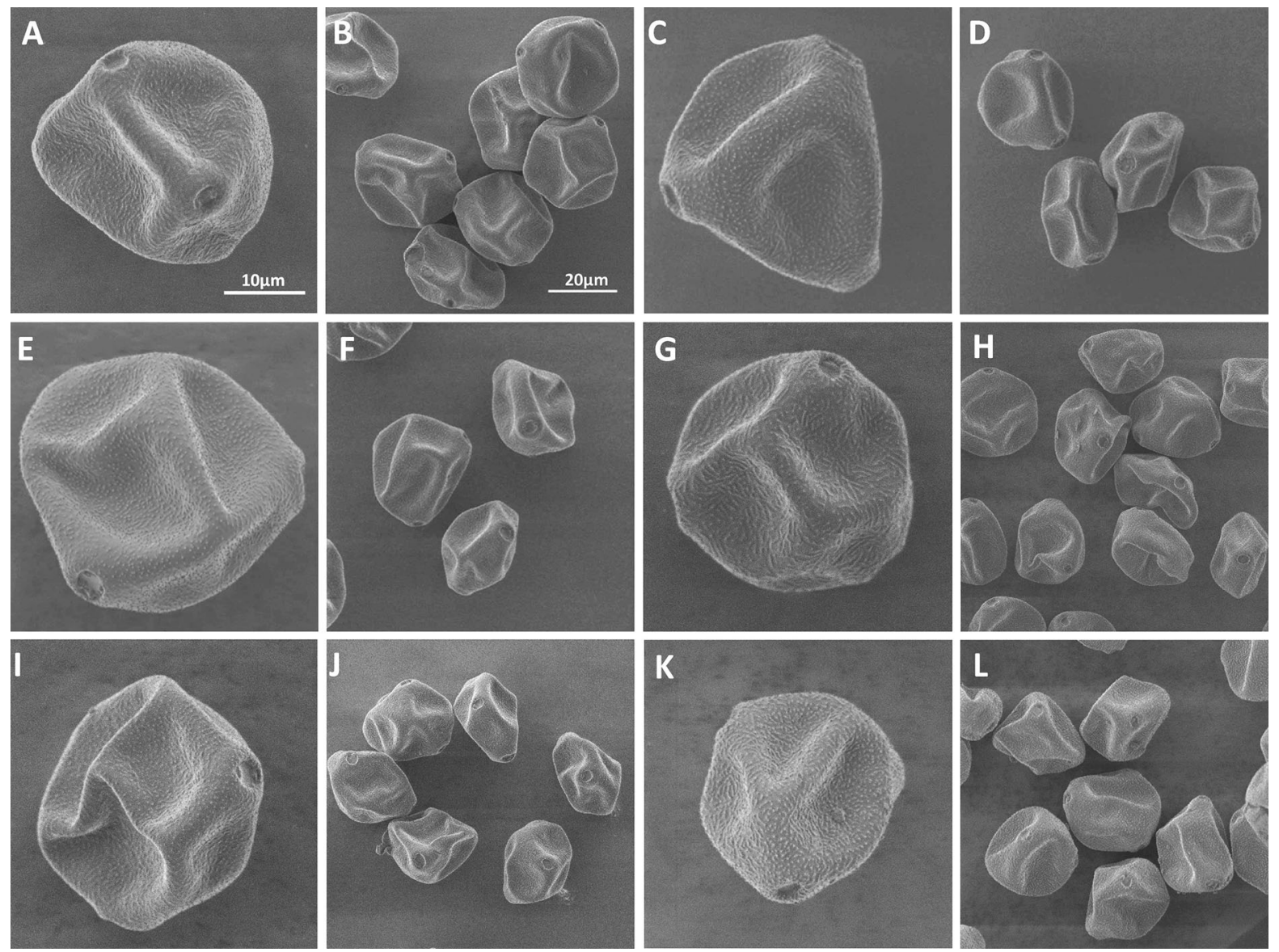

Fig. 1 SEM images of different species of birch pollen grains: a, b B. utilis Doorenbos; c, d B. utilis dahurica; e, f $B$. maximowicziana; $\mathbf{g}, \mathbf{h}$ B. pendula; $\mathbf{i}, \mathbf{j}$ B. dahurica; $\mathbf{k}, \mathbf{l} B$.

humilis. The right-side image is always an overview of pollen. The scale bars correspond to $10 \mu \mathrm{m}$ in left-side images and $20 \mu \mathrm{m}$ in right-side images

Table 1 Descriptive statistics of diameter of pollen grains of chosen Betula species

\begin{tabular}{llllll}
\hline Betula species & Min $(\mu \mathrm{m})$ & $\operatorname{Max}(\mu \mathrm{m})$ & Median $(\mu \mathrm{m})$ & Mean $(\mu \mathrm{m})$ & SD $(\mu \mathrm{m})$ \\
\hline B. utilis Doorenbos a & 28.15 & 37.06 & 32.685 & 32.614 & 2.009 \\
B. dahurica b & 24.02 & 30.95 & 27.450 & 27.329 & 1.545 \\
B. maximowicziana b & 24.57 & 31.73 & 28.615 & 28.29 & 1.518 \\
B. pendula c & 20.22 & 25.22 & 23.220 & 23.104 & 1.234 \\
B. pubescens c & 20.22 & 26.22 & 22.975 & 22.936 & 1.394 \\
B. humilis c & 17.64 & 26.06 & 22.485 & 2.168 & 1.950 \\
\hline
\end{tabular}

$S D$ standard deviation; arabic letters denominate groups with differences in size of grains, which was proved by Dunn's post hoc test

functional groups were observed, while the spectrum of B. humilis pollen (Fig. 2f) does not show the presence of vibrations at wave number $1460 \mathrm{~cm}^{-1}$, which corresponds to the stretching vibration of the $\mathrm{CH}_{2}$ group derived from proteins and lipids. However, the values of maximum absorbance of individual peaks differ from each other in all six pollen samples, which means that there are quantitative differences among the six pollen species in terms of chemical composition. 

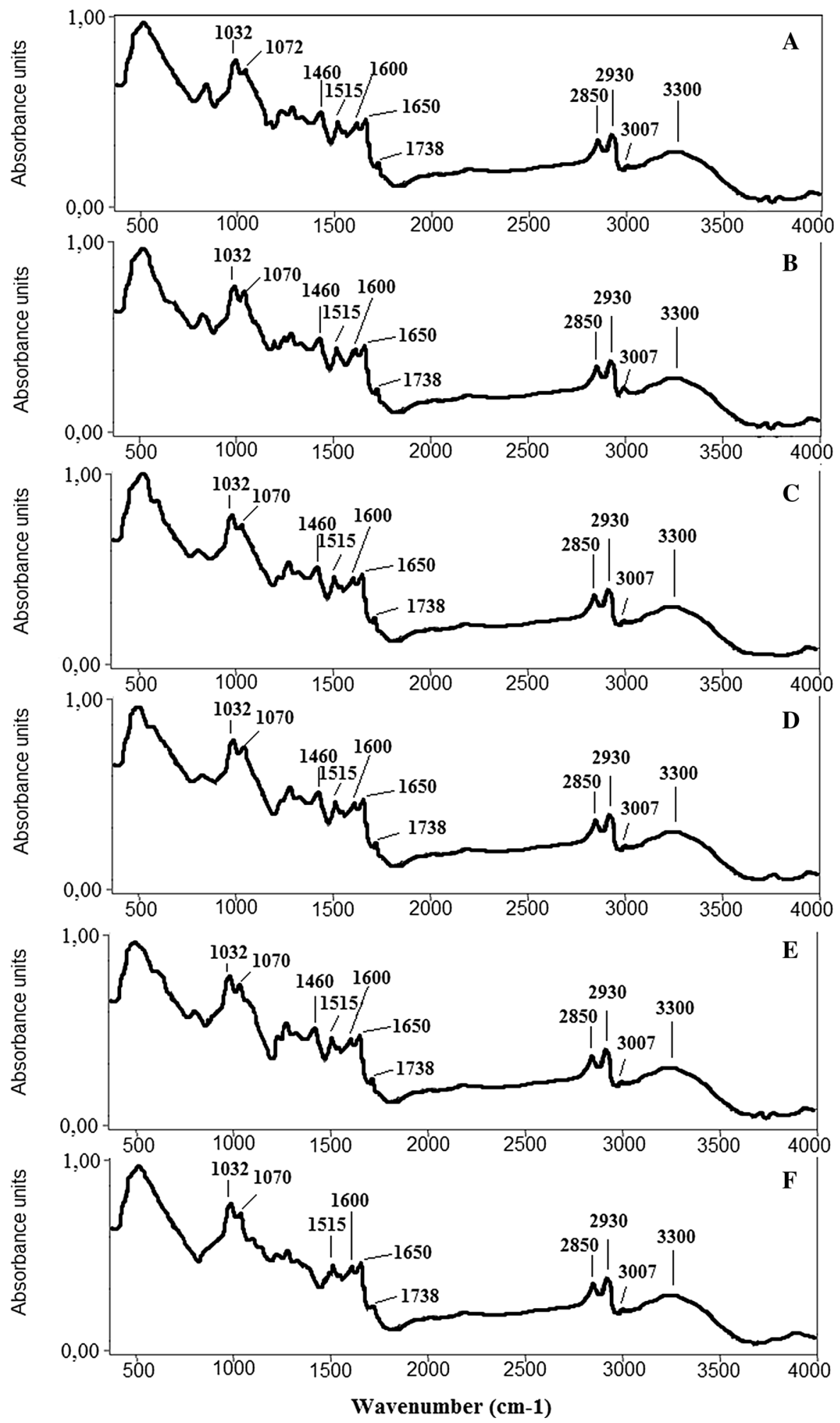

Fig. 2 Offset of average FTIR spectra of Betula pollen: a B. utilis Doorenbos, b B. dahurica, c B. maximowicziana, d B. pendula, e B. pubescens and $\mathbf{f}$ B. humilis 
Table 2 Values of wave numbers with the corresponding vibrations present in pollen of six Betula species

\begin{tabular}{lll}
\hline No. & Wavenumber $\left(\mathrm{cm}^{-1}\right)$ & Vibrations \\
\hline 1 & 1032 & Stretching vibrations of C-O-C group \\
2 & $1000-1075$ & $\mathrm{C}-\mathrm{O}$ stretching \\
3 & $1460^{\mathrm{a}}$ & $\mathrm{CH}_{2}$ stretching \\
4 & $1515-1570$ & $-\mathrm{CNH}$ (amide II) \\
5 & 1600 & $\mathrm{C}=\mathrm{O}$ stretching (proteins) \\
6 & 1650 & $\mathrm{~N}-\mathrm{H}_{2}$ bending (amide I) \\
7 & 1738 & $\mathrm{C}=\mathrm{O}$ stretching (lipids) \\
8 & 2850 & $\mathrm{CH}$ stretching (lipids) \\
9 & 2930 & $\mathrm{CH}$ stretching (lipids) \\
10 & 3007 & $\mathrm{C}=\mathrm{C}$ \\
11 & 3300 & Deformation vibrations of O-H (water) \\
\hline
\end{tabular}

To obtain structural information from the samples, the second derivative from the respective peaks is calculated.

From the calculated second derivative of the FTIR spectra (Fig. 3), it can be noted that the most visible structural differences between each species were observed in the protein $\left(1300-1700 \mathrm{~cm}^{-1}\right)$ and carbohydrates and lipids $\left(1000-1250 \mathrm{~cm}^{-1}\right)$ regions. Moreover, it should be mentioned that in the identification of pollen by FTIR technique, the region in the range between 800 and $1800 \mathrm{~cm}^{-1}$ is the so-called fingerprint region. In this area, the highest differences between species were noticed. Furthermore, significant variations of the second derivative of the FTIR spectra in the protein region may indicate structural changes in proteins fraction between pollen samples. In order to obtain information about the type of secondary structural changes between pollen samples of $\alpha$-helix and $\beta$-harmonica of proteins (Dogan et al. 2007; Misra et al. 2015; Pandey et al. 2010; Mauerer and Lee 2006; Maury et al. 2005), thus curve-fitting analysis of amide I profile was performed (Fig. 4).

Table 3 shows the percentage content and the vibration type of the protein's secondary structures for the six analyzed pollen samples. As the structural changes in proteins between pollen samples are visible only in amide I bonds $\left(1600-1700 \mathrm{~cm}^{-1}\right)$, the curvefitting analysis was performed only for this region (Fig. 4). All peaks corresponding to the secondary structure of proteins are visible in each of the six pollen spectra. The peaks at 1600 and $1620 \mathrm{~cm}^{-1}$ correspond to $\beta$-sheet vibrations. The maximum absorbance at wave number $1650 \mathrm{~cm}^{-1}$ originates from $\alpha$-helix vibrations. Vibrations observed in the curve-fitting analysis of the amide I profile at 1670 and $1690 \mathrm{~cm}^{-1}$ correspond to the $\beta$-turn (Table 4).

The results of HCA showed which Betula species are similar to each other taking into account the data obtained from FTIR. The analysis of the dendrogram revealed two groups of species with distinctly different spectra, as well as one outlying specie (Fig. 5).

According to the chemical composition, cluster analysis shows that three homogeneous groups can be distinguished. The first one includes $B$. pendula (D) and B. pubescens (E), which show the highest similarities. The second group consists of $B$. utilis Doorenbos (A), B. dahurica (B) and of B. maximowicziana $(\mathrm{C})$. B. humilis $(\mathrm{F})$ clearly stands out from all other species (Fig. 5). Also HCA of the protein region (FTIR spectrum between 1500 and $1700 \mathrm{~cm}^{-1}$ ) shows that $B$. humilis $(\mathrm{F})$ is different from all other species (Fig. 6). Protein compositions of B. pendula (D), $B$. pubescens $(\mathrm{E})$, B. maximowicziana $(\mathrm{C})$ and $B$. utilis Doorenbos (A) are very similar to each other. $B$. dahurica (B) is slightly different from this last group.

In addition, HCA was performed on Euclidean distances between pollen diameter values to verify whether the biometric approach may be useful to better differentiate between Betula species. The results presented in Fig. 7 are really similar to the ones shown in Fig. 5, and only small differences concerning the value of Euclidean distances were observed. The similarities between B. maximowicziana (C), B. utilis Doorenbos (A) and B. dahurica (B) are weaker in HCA performed on pollen diameter than in HCA performed on results obtained for FTIR measurements. 
Fig. 3 Second derivative of the FTIR spectra of Betula pollen: a $B$. utilis

Doorenbos, b B. dahurica,

c $B$. maximowicziana, $\mathbf{d} B$. pendula, e $B$. pubescens and f $B$. humilis
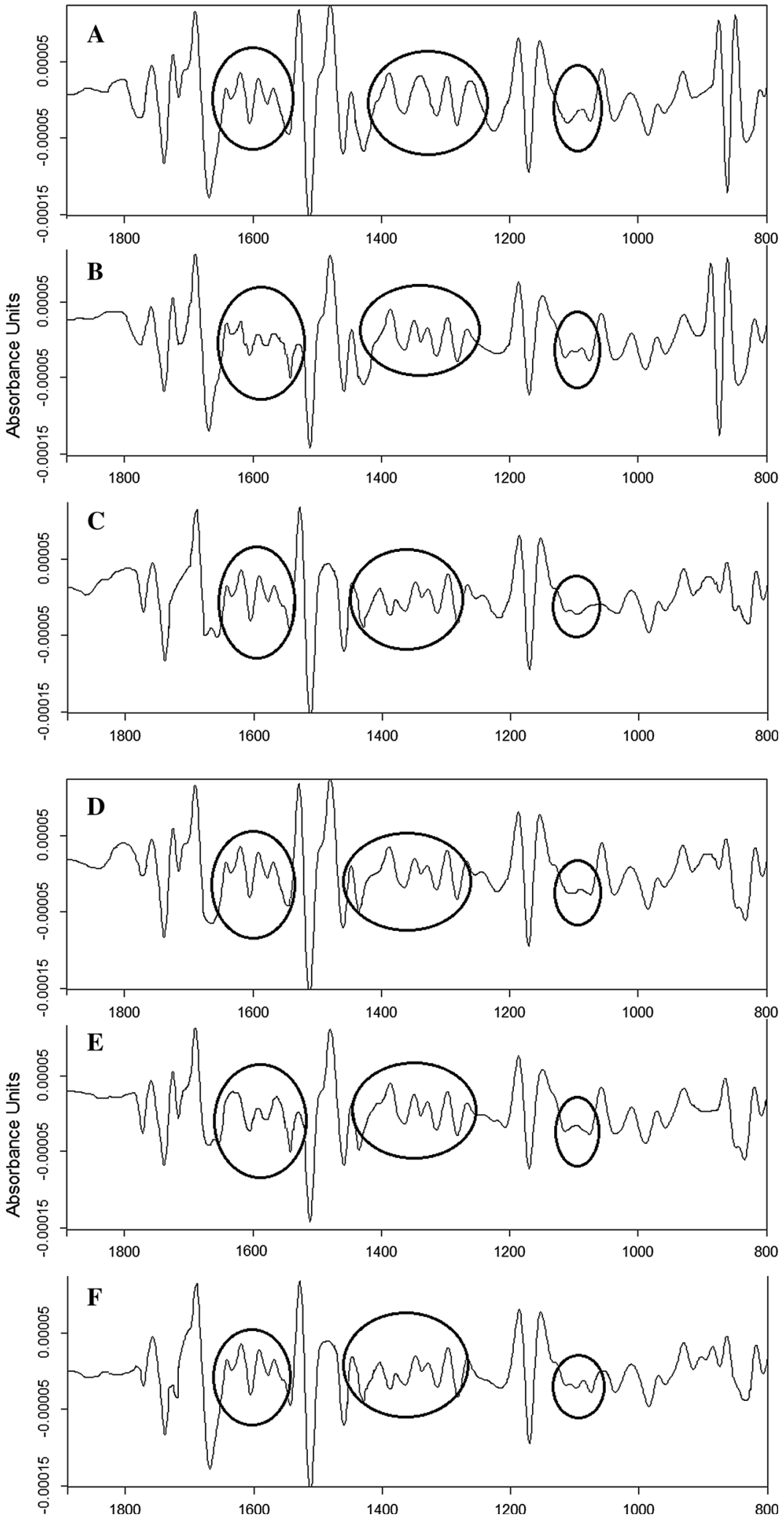

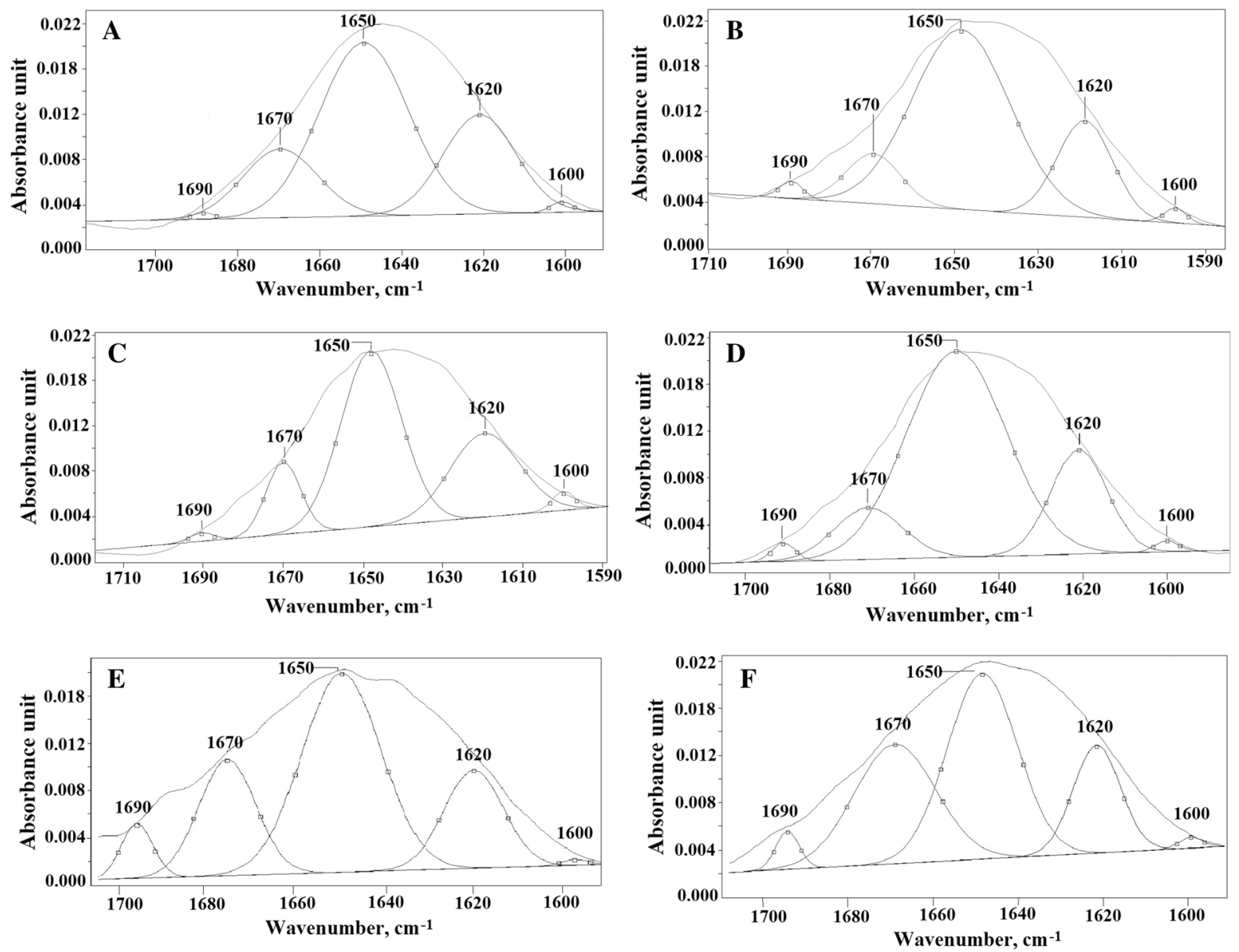

Fig. 4 Curve-fitting analysis of the amide I profile of Betula pollen: a B. utilis Doorenbos, b B. dahurica, c B. maximowicziana, d B. pendula, e B. pubescens and $\mathbf{f}$ B. humilis

Table 3 Curve-fitting analysis of protein's secondary structures of Betula pollen: A-B. utilis Doorenbos, B-B. dahurica, C-B. maximowicziana, $\mathrm{D}-$ B. pendula, $\mathrm{E}-$ B. pubescens, $\mathrm{F}-B$. humilis

\begin{tabular}{|c|c|c|c|c|c|c|c|}
\hline \multirow[t]{2}{*}{ No. } & \multirow[t]{2}{*}{ Wave number $\left(\mathrm{cm}^{-1}\right)$} & \multicolumn{6}{|c|}{ Values $(\%)$} \\
\hline & & A & B & $\mathrm{C}$ & $\mathrm{D}$ & $\mathrm{E}$ & $\mathrm{F}$ \\
\hline 1 & 1600 & 0.8 & 1.5 & 2.3 & 0.4 & 1.1 & 0.8 \\
\hline 2 & 1620 & 25.5 & 20.2 & 30.4 & 10.0 & 20.8 & 19.9 \\
\hline 3 & 1650 & 54.6 & 66.5 & 53.7 & 49.8 & 40.3 & 43.9 \\
\hline 4 & 1670 & 18.8 & 10.40 & 12.5 & 35.9 & 18.3 & 32.5 \\
\hline 5 & 1690 & 0.1 & 1.45 & 1.1 & 4.0 & 19.5 & 2.9 \\
\hline
\end{tabular}

\section{Discussion}

Birch pollen is a frequent object of aerobiological and paleopalynological studies. It contains one of the strongest pollen allergens, and it is also one of the most important components of quaternary pollen spectra. Some Betula species are indicators of different types of vegetation, and based on the presence of their pollen 
Table 4 Wave numbers with the corresponding vibrations of protein secondary structures. Reproduced with permission from Dogan et al. (2007), Misra et al. (2015), Pandey et al. (2010), Mauerer and Lee (2006), Maury et al. (2005)

\begin{tabular}{ll}
\hline Wave number $\left(\mathrm{cm}^{-1}\right)$ & Vibrations \\
\hline 1600 & $\beta$-Sheet \\
1620 & $\beta$-Sheet \\
1650 & $\alpha$-Helisa \\
1670 & $\beta$-Turn \\
1690 & $\beta$-Turn \\
\hline
\end{tabular}

grains in the sediments, paleoclimate can be inferred (Blackmore et al. 2003). Therefore, the ability to distinguish pollen grains to species level is of great importance.

The analysis indicated that B. utilis Doorenbos pollen is easily recognizable from all the others, as it has significantly larger dimensions. B. pubescens, $B$. pendula and $B$. humilis have pollen grains of similar size, even if the results obtained in the present study for two first species clearly differ from the ones reported by other authors (Mäkelä 1996; Karlsdóttir et al. 2007). According to Mäkelä (1996), pollen grains of $B$. pendula $(20-25 \mu \mathrm{m}$ in average) are generally smaller than those of $B$. pubescens (22-26 $\mu \mathrm{m}$ in average). They have stressed that $B$. pubescens is a very variable species and 'small' grains of B. pubescens are not so rare. That is what makes distinguishing between these two species problematic.

Fig. 5 Homogeneous groups according to the highest similarity of entire FTIR spectra of Betula pollen: a $B$. utilis Doorenbos, b B. dahurica, c B. maximowicziana, $\mathbf{d} B$. pendula, e $B$. pubescens and f $B$. humilis
The taxonomy of Betula genus is still challenging. One of the reasons is its ability to create hybrids. The differentiation among species or varieties on the basis of morphology is often difficult, because of phenotypic plasticity and ecotype variation; in this respect, biochemical and genetic methods could be helpful (Keinänen et al. 1999; Järvinen et al. 2004).

There is no literature about using FTIR to distinguish more than two Betula species. However, Atkinson et al. (1997) used IR spectroscopy for discriminating between $B$. pendula, B. pubescens, as well as their hybrids. They analyzed leaves, including the petiole, showing that it is possible to define discriminant functions based on selected spectral wavelengths, able to perform a correct classification in most of cases. However, there is a risk that by increasing the number of spectral wavelengths the discriminant functions will not perform well on other data. Dieterich (1963), Nokes (1979) and Atkinson et al. (1997) showed that a hybrid is more similar to the higher ploidy level parent (e.g., B. pubescens, $2 n=56)$ than to the lower ploidy level parent $(B$. pendula, $2 n=28$ ). Moreover, depending on the plant part, from which the sample was taken, the FTIR spectra are different (Atkinson et al. 1997). They obtained different FTIR spectra from different plant parts, e.g., leaf, stem, pollen, root. Therefore, to perform classification of species using FTIR spectroscopy, the samples collected from the same plant part must be measured. Therefore, in the present study only pollen grains were analyzed by FTIR. Moreover, FTIR spectra of biological systems are very complex,
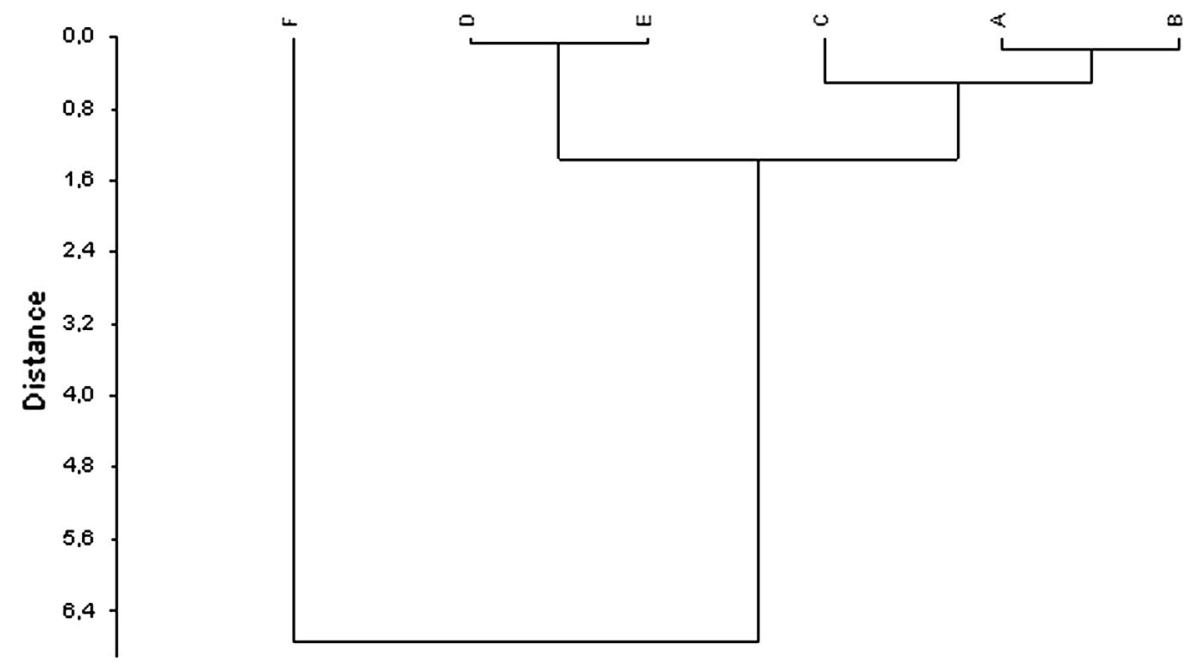


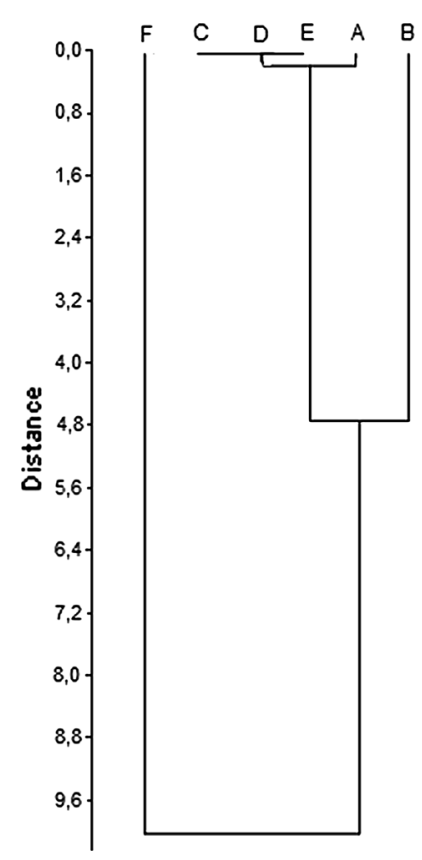

Fig. 6 Homogeneous groups according to the highest similarity of FTIR spectra of Betula pollen in the range between 1500 and $1700 \mathrm{~cm}^{-1}$ a B. utilis Doorenbos, b B. dahurica, c $B$. maximowicziana, $\mathbf{d}$ B. pendula, $\mathbf{e}$ B. pubescens and $\mathbf{f} B$. humilis

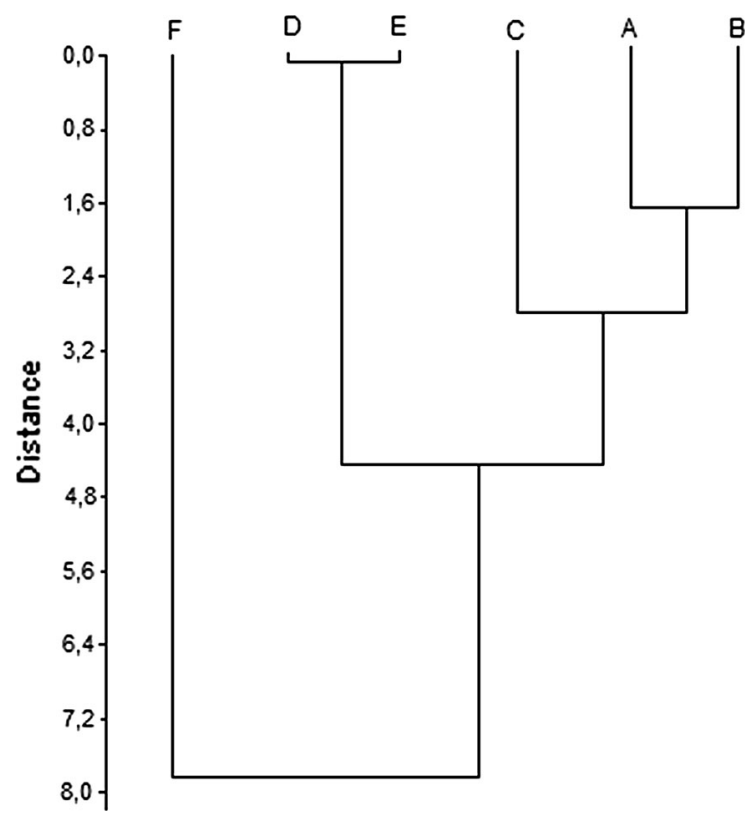

Fig. 7 Homogeneous groups according to the highest similarity of entire FTIR spectra of spectra of Betula pollen and pollen grains diameter: a $B$. utilis Doorenbos, b B. dahurica, c $B$. maximowicziana, $\mathbf{d}$ B. pendula, e $B$. pubescens and $\mathbf{f} B$. humilis being due to the overlapping absorption of the main biomolecules. For this reason, it is necessary to apply an appropriate multivariate analysis, able to process very high-dimensional data, to pull out significant and non-redundant information contained in the spectra (Ami et al. 2013; Lõoke et al. 2011). Moreover, Betula species, including these analyzed in the present study, vary in origin, habitat requirements and form, as well as in the ability to create hybrids (Atkinson 1992; Järvinen et al. 2004). In Poland, the most common species is $B$. pendula (silver birch), which is native for Europe and Northern Asia, as well as in Morocco. $B$. pubescens (downy birch), the second native birch species in Poland occurs also in Greenland, Europe to Russian Far East and N. Iran (Atkinson 1992). Both species belong to subgenus Betula (Järvinen et al. 2004). Although their habitat requirements are different, they have the tendency to create hybrids (Atkinson 1992; Järvinen et al. 2004). On the base of cluster analysis (Fig. 5), we can suppose that the molecular compositions of pollen of these species are very similar. Species belonging to the second group defined by the HCA analysis are not native for Poland or Europe, but grow well, when planted in suitable conditions. These are B. dahurica (Dahurian birch) native from China, Japan and Korea, B. maximowicziana (monarch birch) originating from Japan, as well as $B$. utilis Doorenbos, usually an ornamental tree in urban parks and in large gardens. HCA showed that $B$. humilis, which belongs to Chamaebetula subgenus (Järvinen et al. 2004), stands out from other species. It is native to subarctic and subalpine areas in Eurasia and is a boreal relic for Poland, where it occurs only in few sites and is protected by law (endangered category). It occurs mainly in peatlands and wet meadows as low and strongly branched shrub (Załuski et al. 2001).

Spectroscopy is an effective method of pollen identification, especially when the species are not phylogenetically related to each other. In the case of a strong relationship, the spectra are similar to each other (Zimmermann 2018). In 2017, we examined the chemical composition of hazel pollen (Depciuch et al. 2017), a species closely related to birches (Järvinen et al. 2004). The mere visual comparison of the spectra reveals clear differences, which indicate that the chemical composition of hazel pollen distinctly differs from the chemical composition of pollen of all birch species. 
Summarizing, spectroscopy measurements indicate that the molecular composition of $B$. humilis is clearly distinct from the other species, but the size of the pollen grains does not statistically differ from the size of B. pendula and B. pubescens. On the other hand, the diameter of B. utilis Doorenbos pollen grains is the largest, but its FTIR spectrum is similar to $B$. maximowicziana and $B$. dahurica spectra, whose pollen grains are significantly smaller.

\section{Conclusions}

Distinguishing birch pollen to species level is important in paleoecology and studies dealing with the content of allergenic pollen in air. In the present work, an attempt to distinguish between birch pollen of six species by comparing their chemical composition was undertaken. The obtained results show that FTIR spectroscopy is a fast reliable technique for this purpose. B. humilis is the most outstanding species from the six analyzed samples in terms of chemical composition. It is weakly related to other species; moreover, it is distinguished by specific habitat requirements, the area of origin and a small area of occurrence. It seems that in the case of birches, the chemical composition is related to these characteristics. In this perspective, spectroscopic methods may give an interesting outlook in research concerning ecology or origin of species, and molecular taxonomy. The presented biometric method allowed to distinguish three groups of species, which differ in terms of pollen grains diameters, yet its taxonomic significance is weaker because it relies only on one feature (the size), while spectroscopy analyzes the content of many chemical compounds. The results show that the pollen collected from the flower can be easily distinguished by means of spectroscopy, and thus, this method has the potential to be used in continuous monitoring of aeroallergens. Biometric analysis could be used as a preliminary tool, while spectroscopy would be applied as a more specific technique. At the moment, however, there are no methodological solutions allowing to collect samples from air, which could be subjected to spectroscopy.

Acknowledgements Grant No. UMO-2014/13/B/ST5/04497 is acknowledged for the financial support of the SEM Tescan Vega 3 instrument. We would like to thank Mrs Elżbieta Żygała from Bolestraszyce Arboretum for her kind help in collecting materials.

Open Access This article is distributed under the terms of the Creative Commons Attribution 4.0 International License (http:// creativecommons.org/licenses/by/4.0/), which permits unrestricted use, distribution, and reproduction in any medium, provided you give appropriate credit to the original author(s) and the source, provide a link to the Creative Commons license, and indicate if changes were made.

\section{References}

Ami, D., Mereghetti, P., \& Doglia, S. M. (2013). Multivariate analysis for Fourier transform infrared spectra of complex biological systems and processes. In L. Valim de Freitas \& A. P. Barbosa Rodrigues de Freitas (Eds.), Multivariate analysis in management engineering and the sciences (pp. 189-220). Rijeka: InTech.

APG II. (2003). An update of the Angiosperm Phylogeny Group classification for the orders and families of flowering plants: APG II. Botanical Journal of the Linnean Society, 141, 399-436.

Atkinson, M. D. (1992). Betula pendula Roth (B. verrucosa Erth.) and B. pubescens Ehrh. Journal of Ecology, 80, 837-870.

Atkinson, M. D., Jervis, A. P., \& Sangha, R. S. (1997). Discrimination between Betula pendula, Betula pubescens and their hybrids using near-infrared spectroscopy. Canadian Journal of Forest Research, 27, 1896-1900.

Bağcığlu, M., Kohler, A., Seifert, S., Kneipp, J., \& Zimmermann, B. (2017). Monitoring of plant-Environment interactions by high-throughput FTIR spectroscopy of pollen. Methods in Ecology and Evolution, 8(7), 870-880.

Bağcığlu, M., Zimmermann, B., \& Kohler, A. (2015). A multiscale vibrational spectroscopic approach for identification and biochemical characterization of pollen. PLoS ONE, 10(9), e0137899.

Birks, S. (1968). The identification of Betula nana pollen. New Phytologist, 67, 309-314.

Blackmore, S., Steinmann, J. A., Hoen, P. P., \& Punt, W. (2003). The Northwest European Pollen Flora 65: Betulaceae and Corylaceae. Review of Palaeobotany and Palynology, 123, 71-98.

Buta, E., Cantor, M., Ştefan, R., Pop, R., Mitre, I., Buta, M., \& Sestraş, R. E. (2015). FT-IR characterization of pollen biochemistry, viability, and germination capacity in Saintpaulia H. Wendl. Genotypes. Journal of Spectroscopy, 2015, 1-7.

Caseldine, C. (2001). Changes in Betula in the Holocene record from Iceland-A palaeoclimatic record or evidence for early Holocene hybridisation? Review of Palaeobotany and Palynology, 117, 139-152.

Chen, L., Wilson, R. H., \& McCann, M. C. (1997). Infrared microspectroscopy of hydrated biological systems: Design and construction of a new cell with atmospheric control for the study of plant cell walls. Journal of Microscopy, 188, 62-71. 
Clegg, B. F., Tinner, W., Gavin, D. G., \& Hu, F. S. (2005). Morphological differentiation of Betula (birch) pollen in northwest North America and its paleoecological application. The Holocene, 15, 229-237.

Dell'Anna, R., Lazzeri, P., Frisanco, M., Monti, F., Malvezzi, C. F., Gottardini, E., et al. (2009). Pollen discrimination and classification by Fourier transform infrared (FT-IR) microspectroscopy and machine learning. Analytical and Bioanalytical Chemistry, 394(5), 1443-1452.

Depciuch, J., Kasprzyk, I., Roga, E., \& Parlińska-Wojtan, M. (2016). Analysis of morphological and molecular composition changes in allergenic Artemisia vulgaris L. pollen under traffic pollution using SEM and FTIR spectroscopy. Environmental Science and Pollution Research, 23, 23203-23214.

Depciuch, J., Kasprzyk, I., Sadik, O., \& Parlińska-Wojtan, M. (2017). FTIR analysis of molecular composition changes in hazel pollen from unpolluted and urbanized areas. Aerobiologia, 33(1), 1-12.

Dieterich, H. (1963). Untersuchungen zum ökologischen und genetischen Birkenproblem. Silvae Genetica, 12(110), 124.

Dogan, A., Siyakus, G., \& Severcan, F. (2007). FTIR spectroscopic characterization of irradiated hazelnut (Corylus avellana L.). Food Chemistry, 100, 1106-1114.

Erdtman, G. (1952). Pollen morphology and plant taxonomy: Angiosperms. Waltham, MA: Almqvist \& Wiksell.

Frenguelli, G., \& Kasprzyk, I. (2015). Description of pollen grains. In I. Kasprzyk \& M. Smith (Eds.), Manual for aerobiology. Rzeszów: Wyd. Univ. Rzeszow.

Gottardini, E., Rossi, S., Cristofolini, F., \& Benedetti, L. (2007). Use of Fourier transform infrared (FT-IR) spectroscopy as a tool for pollen identification. Aerobiologia, 23, 211-219.

Järvinen, P., Palme, A., Morales, L. O., Lännepää, M., Keinänen, M., Sopanen, T., et al. (2004). Phylogenetic relationships of Betula species (Betulaceae) based on nuclear $A D H$ and chloroplast MATK sequence. American Journal of Botany, 91(11), 1834-1845.

Julier, A. C. M., Jardine, P. E., Coe, A. L., Gosling, W. D., Lomax, B. H., \& Fraser, W. T. (2016). Chemotaxonomy as a tool for interpreting the cryptic diversity of Poaceae pollen. Review of Palaeobotany and Palynology, 235, 140-147.

Karlsdóttir, L., Hallsdóttir, M., Thorsson, A Th, \& AnamthawatJónsson, K. (2008). Characteristics of pollen from natural triploid Betula hybrids. Grana, 47, 52-59.

Karlsdóttir, L., Thorsson, A. T., Hallsdóttir, M., Sigurgeirsson, A., Eysteinsson, T., \& Anamthawat-Jónsson, K. (2007). Differentiating pollen of Betula species from Iceland. Grana, 46, 78-84.

Keinänen, M., Julkunen-Tuttto, R., Rousi, M., \& Tahvanainen, J. (1999). Taxonomic implications of phenoloc variation in leaves of birch (Betula L.) species. Biochemical Systematics and Ecology, 27, 243-254.

Kim, S. W., Ban, S. H., Chung, H., Cho, S., Chung, H. J., Choi, P. S., et al. (2004a). Taxonomic discrimination of flowering plants by multivariate analysis of Fourier transform infrared spectroscopy data. Plant Cell Reports, 23, 246-250.

Kim, S. W., Ban, S. H., Chung, H. J., Choi, D. W., Choi, P. S., Yoo, O. J., et al. (2004b). Taxonomic discrimination of higher plants by pyrolysis mass spectrometry. Plant Cell Reports, 22, 519-522.

Lahlali, R., Jiang, Y. F., Kumar, S., Karunakaran, C., Liu, X., Borondics, F., et al. (2014). ATR-FTIR spectroscopy reveals involvement of lipids and proteins of intact pea pollen grains to heat stress tolerance. Frontiers in Plant Science, 5, 747.

Lõoke, M., Kristjuhan, K., \& Kristjuhan, A. (2011). Extraction of genomic dna from yeasts for PCR based applications. BioTechniques, 50(5), 325-328.

Mäkelä, E. M. (1996). Size distinctions between Betula pollen types-A reviews. Grana, 35(4), 248-256.

Mauerer, A., \& Lee, G. (2006). Changes in the amide I FT-IR bands of poly-L-lysine on spray-drying from $\alpha$-helix, $\beta$ sheet or random coil conformations. European Journal of Pharmaceutics and Biopharmaceutics, 62, 131-142.

Maury, M., Murphy, K., Kumar, S., Mauerer, A., \& Lee, G. (2005). Spray-drying of proteins: Effects of sorbitol and trehalose on aggregation and FT-IR amide I spectrum of an immunoglobulin G. European Journal of Pharmaceutics and Biopharmaceutics, 59, 251-261.

Misra, N. N., Kaur, S., Tiwari, B. K., Kaur, A., Singh, N., \& Cullen, P. J. (2015). Atmospheric pressure cold plasma (ACP) treatment of wheat flour. Food Hydrocolloids, 44, $115-121$.

Mohani, N., Ahmad, M., \& Jahan, N. (2014). Evaluation of phytoconstituents of three plants Acorus calamus Linn Artemisia absinthium Linn and Bergenia himalaica boriss by FTIR spectroscopic analysis. Pakistan Journal of Pharmaceutical Sciences, 27(6), 2251-2255.

Nokes, D. C. B. (1979). Biosystematic studies of Betula pendula Roth and B. pubescens Ehrh. in Great Britain. Ph.D. thesis (CNAA), The Polytechnic, Wolverhampton, UK.

Pandey, P., Samanta, A. K., Bandyopadhyay, B., \& Chakraborty, T. (2010). CH center dot center dot center dot O interaction lowers hydrogen transfer barrier to keto-enol tautomerization of beta-cyclohexanedione: Combined infrared spectroscopic and electronic structure calculation study. Journal of Molecular Structure, 975, 343-348.

Pappas, C. S., Tarantilis, P. A., Harizanis, P. C., \& Polissiou, M. G. (2003). New method for pollen identification by FT-IR spectroscopy. Applied Spectroscopy, 57, 23-27.

Parducci, L., \& Suyama, Y. (2011). Single-pollen genotyping of Holocene lake sediments. In Y. Isagi \& Y. Suyama (Eds.), Single-pollen genotyping (pp. 101-109). Tokyo: Springer.

Rather, M. A., Dar, B. A., Shah, W. A., Prabhakar, A., Bindu, K., Banday, J. A., et al. (2014). Comprehensive GC-FID, GC-MS and FT-IR spectroscopic analysis of the volatile aroma constituents of Artemisia indica and Artemisia vestita essential oils. Arabian Journal of Chemistry, 5, 1-6.

Reitsma, T. J. (1969). Size morphology of recent pollen grains under different treatments. Review of Palaeobotany and Palynology, 9, 179-201.

Rubio-Diaz, D. E., De Nardo, T., Santos, A., de Jesus, S., Francis, D., \& Rodriguez-Saona, L. E. (2010). Profiling of nutritionally important carotenoids from genetically-diverse tomatoes by infrared spectroscopy. Food Chemistry, 120(1), 282-289.

Stewart, D., Yahiaoui, N., McDougall, G. J., Myton, K., Marque, C., Boudet, A. M., et al. (1997). Fourier-transform infrared and Raman spectroscopic evidence for the 
incorporation of cinnamaldehydes into the lignin of transgenic tobacco (Nicotiana tabacum L.) plants with reduced expression of cinnamyl alcohol dehydrogenase. Planta, 201, 311-318.

Załuski, T., Pisarek, W., Kucharczyk, M., \& Kamińska, A. M. (2001). Betula humilis Schrank. In R. Kaźmierczakowa \& K. Zarzycki (Eds.), Polska czerwona księga roślin (pp. 79-81). Kraków: W. Szafer Institute of Botany, Polish Academy of Sciences.

Zhou, L.-J., Pei, K.-Q., Zhou, B., \& Ma, K.-P. (2007). Molecular approach to species identification of chenopodiaceae pollen grains in surface soil. American Journal of Botany, 94(3), 477-481.

Zimermann, B., \& Kohler, A. (2014). Infrared spectroscopy of pollen identifies plant species and genus as well as environmental conditions. PLOS ONE, 9(4), e95417.
Zimmerman, B. (2010). Characterization of pollen by vibrational spectroscopy. Applied Spectroscopy, 64(12), 1364-1373.

Zimmermann, B. (2018). Chemical characterization and identification of Pinaceae pollen by infrared microspectroscopy. Planta, 247, 171-180.

Zimmermann, B., Bağcioğlu, M., Tafinstseva, W., Kohler, A., Ohlson, M., \& Fjellheim, S. (2017). A high-throughput FTIR spectroscopy approach to assess adaptive variation in the chemical composition of pollen. Ecology and Evolution, 7(24), 10839-10849.

Zimmermann, B., Tkalcec, Z., Mesic, A., \& Kohler, A. (2015). Characterizing aeroallergens by infrared spectroscopy of fungal spores and pollen. PLOS ONE, 10(4), e0124240. 